\title{
After Revolution and Democratization: Conceptualizing the 18th Brumaire and Regimes of the two Bonapartes.
}

Peter Baehr

\section{(2) OpenEdition}

Journals

Édition électronique

URL : https://journals.openedition.org/ahrf/947

DOI : 10.4000/ahrf.947

ISSN : 1952-403X

Éditeur :

Armand Colin, Société des études robespierristes

Édition imprimée

Date de publication : 1 décembre 1999

Pagination : 789-790

ISSN : 0003-4436

\section{Référence électronique}

Peter Baehr, «After Revolution and Democratization: Conceptualizing the 18th Brumaire and Regimes of the two Bonapartes. », Annales historiques de la Révolution française [En ligne], 318 | octobredécembre 1999, mis en ligne le 21 avril 2004, consulté le 24 avril 2022. URL : http:// journals.openedition.org/ahrf/947 ; DOI : https://doi.org/10.4000/ahrf.947

Ce document a été généré automatiquement le 24 avril 2022.

Tous droits réservés 


\title{
After Revolution and Democratization: Conceptualizing the 18th Brumaire and Regimes of the two Bonapartes.
}

\author{
Peter Baehr
}

\section{RÉFÉRENCE}

After Revolution and Democratization: Conceptualizing the 18th Brumaire and Regimes of the two Bonapartes, 9-11 avril 1999, Hunter College, The City University of New York.

1 Le bicentenaire du coup d'État de Bonaparte a donné lieu à une rencontre organisée par Melvin Richter à Hunter College, co-sponsorisée par le German Historical Institute, et qui était aussi la réunion internationale de la Conference for the Study of Political Thought. Elle a réuni un grand nombre de chercheurs, historiens, sociologues, théoriciens et spécialistes de science politique. Les débats ont été centrés sur la nature et le legs des deux empires napoléoniens. La conférence s'organisait en cinq unités thématiques suivies d'une table ronde. Les contributions de la première séquence celle d'Isser Woloch sur la transition du Consulat à l'Empire et celle de Wulf Wülfing sur le mythe perpétré par les écrits de Goethe, Heine et Nietzsche - étaient consacrées aux «deux empires dans l'histoire européenne, mémoire et pensée politique», et commentées par Cheryl Welch, qui a attiré l'attention sur l'ambivalence des interprétations au xixe siècle et conclu au peu de crédit accordé à la fin du xxe siècle à ce qu'elle nomme le «Napoléonic cautionary tale».

Dans la seconde séquence dédiée aux Bonapartes et à la création de l'État moderne européen, Jack Hayward proposait le gaullisme et le bonapartisme comme types classiques de leadership «héroïque» et T.C.W. Blanning, traitant des relations entre la France et la Prusse, a mis l'accent sur les conséquences de la politique des deux 
empereurs. Dans son commentaire, Charles Tilly développait une typologie des relations entre souverain, chefs, nation et État, soulignant l'intérêt des contributions en ce qui concerne les relations entre organisation militaire et autorité politique et entre autorité politique et citoyenneté. Sur le problème de l'historiographie et de la conceptualisation du régime - bonapartisme ou césarisme - objet de la troisième séquence, Arthur Eckstein présentait l'administration impériale comme une menace intérieure pour l'ordre politique établi dans un État de droit. Faut-il conclure avec Wolfgang Wippermann à la continuité (et non à l'identité) entre bonapartisme et fascisme? Commentant ces contributions, Zwi Yavetz a insisté sur la nécessité de distinguer différents types de fascisme.

3 «Les Bonapartes et leurs empires dans l'histoire de la pensée politique», quatrième thème traité, concernait exclusivement le xixe siècle. Après avoir discuté de la prolifération des termes pour qualifier les nouvelles formes de pouvoir (césarisme, impérialisme, bonapartisme), Melvin Richter se concentrait sur l'analyse de Tocqueville: selon lui, après de nombreuses oscillations, Tocqueville a jugé les Bonapartes, leurs coups d'État et leurs empires comme un phénomène moderne, postrévolutionnaire et post-démocratique. Examinant la réponse des conservateurs en Prusse, David Barclay concluait à la complexité des réactions au milieu du siècle, qui vont de l'antipathie hautement conservatrice au crytobonapartisme. Le commentaire de Jerrold Seigel développait le thème de la multiplicité des conservatismes.

4 Les nouveaux types de domination ont fait l'objet des trois contributions de la cinquième séquence sur «Bonapartisme/césarisme dans la pensée politique du xxe siècle». Peter Baehr a traité de la théorie de Max Weber sur le césarisme positif et négatif, et du passage chez lui du concept politique de césarisme à la catégorie sociologique de «charisme». Chez Gramsci, selon Benedetto Fontana, la notion de césarisme s'inscrit dans sa tentative de comprendre la victoire du fascisme et l'échec, non seulement de la gauche révolutionnaire, mais du libéralisme et des institutions libérales en général. John McCormick a mis en valeur la manière dont la doctrine de la dictature chez Carl Schmitt s'effondre dans le césarisme, et a défendu l'idée que le constitutionnalisme libéral résiste mieux aux crises que Carl Schmitt ne l'envisageait. Dans son commentaire, David Kettler offrait quelques observations pertinentes sur la critique gramscienne du libéralisme et la compréhension de la dictature chez Schmitt.

5 La conférence s'est achevée par une table ronde qui a réuni entre autres Andrew Arato, Peter Baehr, T.C.W. Blanning, J.G.A. Pocock et Zwi Yavetz. Un des thèmes récurrents de la discussion a été l'étendue des continuités ou des ruptures entre le pouvoir bonapartiste et ses antécédents absolutistes et ses successeurs fascistes. Les actes de cette rencontre seront publiés par Cambridge University Press. 